\title{
Pseudomonas Aeruginosa-induced Lung and Pleural Injury in Sheep Differential Protective Effect of Circulating versus Alveolar Immunoglobulin G Antibody
}

\author{
J. F. Pittet, * M. A. Matthay, ${ }^{*}$ G. Pier, ${ }^{*}$ M. Grady, * and J. P. Wiener-Kronish * \\ *Cardiovascular Research Institute and Departments of Anesthesia and Medicine, University of California, \\ San Francisco, California 94143; and ${ }^{\ddagger}$ Channing Laboratory, Department of Medicine, \\ Brigham and Women's Hospital, Harvard Medical School, Boston, Massachusetts 02115
}

\section{Abstract}

The overall objective of these studies was to determine whether IgG antibody to Pseudomonas aeruginosa would modify the acute lung and pleural injury that developed over $24 \mathrm{~h}$ after the instillation of $10^{10}$ live $P$. aeruginosa into the distal airspaces of one lung in unanesthetized sheep. Using a quantitative experimental model to measure protein permeability across the alveolar epithelial, lung endothelial, and pleural mesothelial barriers, the effect of IgG antibody to $P$. aeruginosa was examined under four different experimental conditions. First, the effect of IgG antibody to $P$. aeruginosa in the circulation was examined by instilling $10^{10}$ live $P$. aeruginosa in $5 \%$ ovine albu$m$ min in sheep that had been vaccinated. Under these conditions, the presence of circulating IgG antibody to $P$. aeruginosa reduced lung endothelial injury but did not modify the lung epithelial or pleural injury caused by intraalveolar $P$. aeruginosa. Therefore, the second experimental protocol determined the effect of instilling immune serum from a sheep that had been vaccinated so that IgG antibody to $P$. aeruginosa was present in both the circulation and in the airspaces along with instillation of live bacteria. Under these conditions, injury to the lung endothelium, alveolar epithelium, and pleural space was completely prevented. Therefore, the third protocol examined the protective effect of instillation of IgG antibody to $P$. aeruginosa in the airspaces concurrent with the live bacteria. Interestingly, intraalveolar IgG antibody to $\boldsymbol{P}$. aeruginosa prevented all evidence of lung epithelial and pleural injury, and this effect was associated with a marked decrease in the number of viable bacteria in the lung after $24 \mathrm{~h}$. Therefore, the fourth protocol examined the prophylactic effect of instillation of the specific IgG antibody to $P$. aeruginosa $24 \mathrm{~h}$ before instillation of the bacteria. With this prophylactic regimen, epithelial, endothelial, and pleural injury were prevented, and there was a significant decrease in the number of bacteria recovered from the lung. Thus, delivery of IgG antibody to $P$. aeruginosa the distal airspaces of the lung alone may provide a novel therapeutic approach to preventing acute pulmonary infection caused by $\boldsymbol{P}$. aeruginosa. (J. Clin. Invest. 1993. 92:1221-1228.) Key words: Pseudomonas aeruginosa $\bullet$ pneumonia $\bullet$ alveolar epithelium • pleural empyema $\bullet$ immunization $\bullet$ host immunity $\bullet$ lung

Address correspondence to Jeanine P. Wiener-Kronish, M.D., Box 0130, Cardiovascular Research Institute, University of California, San Francisco, CA 94143.

Received for publication 24 September 1992 and in revised form 24 March 1993.

J. Clin. Invest.

(c) The American Society for Clinical Investigation, Inc.

$0021-9738 / 93 / 09 / 1221 / 08 \quad \$ 2.00$

Volume 92, September 1993, 1221-1228

\section{Introduction}

Pseudomonas aeruginosa is the most frequently isolated pathogen from patients with nosocomial pneumonia (1). Despite the use of potent antibiotics, the mortality rate of $P$. aeruginos pneumonia remains between 50 and $80 \%$ (2), establishing the need for new treatment modalities or improved prophylactic measures. Earlier studies have established that serotype-specific humoral immunity results in a significant augmented host defense against blood-borne $P$. aeruginosa (3-5). These studies have also suggested that the most protective antibodies against $P$. aeruginosa are opsonic rather than bactericidal, thus providing a rationale for $P$. aeruginosa immunization strategies that emphasize augmentation of humoral rather than cellmediated immunity (3). In contrast to older vaccines, which contained the whole endotoxin antigen, a Pseudomonas vaccine containing a high molecular weight, immunogenic $O$-specific polysaccharide antigen, but lacking the toxic lipid A component, has been shown to be well tolerated and immunogenic in normal human volunteers (6). This vaccine also has been shown to achieve a plasma level of IgG antibody to $P$. aeruginosa comparable to the levels measured in patients who survived $P$. aeruginosa sepsis $(7,8)$. Also, immunization with $P$. aeruginosa $O$-specific polysaccharide antigen has improved survival after a homologous bacterial challenge in both burned and granulocytopenic mice and in a model of pneumonia in guinea pigs $(9,10)$.

However, the magnitude of protection provided by active immunization against $P$. aeruginos $a$ in modulating the bacterial injury to the different barriers of the lung has not specifically been studied. We have previously developed an experimental animal model that quantifies liquid, protein, and cellular movement across the alveolar epithelial, lung endothelial, and visceral pleural barriers of the intact lung in normal and pathological conditions (11-13). We have also reported that $P$. aeruginosa pneumonia causes injury to the lung epithelial barrier in unanesthetized sheep studied over $24 \mathrm{~h} \mathrm{(13).}$

Therefore, the first objective of these studies was to determine the value of IgG antibody to $P$. aeruginosa, elicited by active immunization against $P$. aeruginosa (Fisher type 1 ), in modulating the lung and pleural injury caused by the instillation of homologous $10^{10}$ live $P$. aeruginosa bacteria into the airspaces of awake sheep. In these initial studies, circulating IgG antibody to $P$. aeruginos $a$ alone did not prevent the bacterial injury to the alveolar epithelium nor the formation of protein-rich pleural effusions. Therefore, another group of experiments examined the effect of instilling autologous immune serum from vaccinated sheep into the airspaces concurrent with the instillation of live $P$. aeruginosa bacteria to test whether the presence of IgG antibody to $P$. aeruginosa in both the circulation and the airspaces of the lung was beneficial. These studies demonstrated complete protection against all in- 
jury from $P$. aeruginosa. Therefore, we tested the hypothesis that IgG antibody to $P$. aeruginos $a$ in the airspaces alone could provide significant protection against $P$. aeruginosa-induced acute lung and pleural injury. In one group of sheep, IgG antibody to $P$. aeruginosa was instilled into the airspaces in nonvaccinated sheep concurrent with instillation of $P$. aeruginosa and, in the final group of sheep, the IgG antibody was instilled $24 \mathrm{~h}$ before the instillation of the bacteria.

\section{Methods}

\section{Surgical preparation and ventilation}

A total of 42 female and wethered yearling sheep $(31 \pm 4 \mathrm{~kg}$; mean $\pm S D)$ were studied. All of the sheep were initially given pentothal $(30 \mathrm{mg} /$ $\mathrm{kg}$ ), intubated, and ventilated with a constant-volume pump (Harvard Apparatus, Millis, MA) at a tidal volume of 400-500 ml (13-15 ml/ $\mathrm{kg}$ ) with a peak inspiratory pressure of $15-20 \mathrm{~cm} \mathrm{H}_{2} \mathrm{O}$ and a positive end-expiratory pressure of $5 \mathrm{~cm} \mathrm{H}_{2} \mathrm{O}$. The respiratory rate was adjusted to achieve an arterial partial pressure of carbon dioxide between 30 and $40 \mathrm{mmHg}$. Anesthesia was maintained with $1.0-1.5 \%$ halothane mixed with supplemental oxygen (40-60\%). Catheters were inserted into the carotid artery and the external jugular vein. Then, the sheep were placed in a prone position with their head and thorax elevated at a $5^{\circ}$ angle to maintain the lower lung lobes in a slightly dependent position. The preparatory surgery required $\sim 45-60 \mathrm{~min}$. All experiments were done in compliance with the University of California San Francisco Animal Care Committee rules and all protocols were approved.

\section{Preparation of instillate}

When autologous serum was used as the instillate, the sheep had $250 \mathrm{ml}$ of blood drawn the day before the experiment to prepare autologous serum. The blood was withdrawn using sterile technique, clotted, and centrifuged to obtain serum. The serum was refrigerated overnight and, the next morning, the solution was filtered through a $0.2-\mu \mathrm{m}$ filter (Nalge Co., Rochester, NY), and $10 \mathrm{mg}$ of anhydrous Evan's blue and $15 \mu \mathrm{Ci}$ of ${ }^{125}$ I-labeled HSA (Merck-Frosst, Quebec, Canada) were added to the sheep's serum, as we have done in earlier studies (11-13). Evan's blue was used to be certain that the instilled serum was confined to the instilled lower lobe. A sample of the labeled serum was saved for radioactivity counts and wet/dry weight ratio measurements so that the dry weight of the serum could be subtracted from the final lung water calculation.

In experiments in which $5 \%$ ovine albumin was instilled, a 5.0 $\mathrm{g} / 100 \mathrm{ml}$ solution in Ringer's lactate that was isosmolar with plasma was prepared; the solution was filtered through a $0.2-\mu \mathrm{m}$ filter, and the tracers were added.

In experiments in which IgG antibody to $P$. aeruginosa was instilled, the antibody was isolated from serum obtained from an immunized donor sheep by affinity chromatography with protein $\mathrm{G}$-agarose (Affinica; Schleicher \& Shuell, Keene, NH). Sheep IgG binds specifically to protein $\mathrm{G}$ in an alkaline, concentrated salt buffer ( $\mathrm{pH} \mathrm{8.9,1.5}$ $\mathrm{M}$ glycine, $3 \mathrm{M} \mathrm{NaCl}$ ) and is eluted at low $\mathrm{pH}$, low ionic strength ( $\mathrm{pH}$ $2.9,0.2 \mathrm{M}$ glycine). Crossed immunoelectrophoresis of the bound protein fraction showed that it contained only IgG with no other sheep serum protein peak. Then, IgG antibody to $P$. aeruginosa was mixed with ovine albumin and Ringer's lactate to prepare a 5\% protein solution, filtered through a $0.2-\mu \mathrm{m}$ filter, and the protein tracers (see below) were then added. In the final group of experiments, the IgG antibody to $P$. aeruginosa in lactated Ringer's (same concentration as in sheep plasma) was instilled $24 \mathrm{~h}$ before the instillation of the $5 \%$ ovine albumin solution containing the bacteria.

\section{General protocol}

For all experimental studies, the following general protocol was used. After surgery, a 1-h baseline period was required before alveolar liquid instillation. Using a fiberoptic bronchoscope (Machida America Inc., Norwood, $\mathrm{NJ}$ ), $3 \mathrm{ml} / \mathrm{kg}$ of the instillate was instilled (see specific protocols) into the right lower lobe. By using a three-way t-piece adapter on the endotracheal tube, ventilation was maintained during the bronchoscopy. At the end of instillation, $10 \mu \mathrm{Ci}$ of ${ }^{131}$ I-labeled human albumin were injected intravenously. This vascular tracer was used to calculate the flux of plasma protein entering the airspaces of the lungs ( see below). Then, the sheep were allowed to recover from anesthesia and were extubated when they were awake and spontaneously breathing. They were placed in a metabolic cart for $24 \mathrm{~h}$ with free access to food and water.

$24 \mathrm{~h}$ later they were given intravenous ketamine $(10 \mathrm{mg} / \mathrm{kg})$ and exsanguinated. The lungs were removed through a sternotomy and 1-2 $\mathrm{ml}$ of alveolar liquid was obtained by passing a 3-mm-diameter catheter into the distal airways (11-13). After centrifugation, the radioactivity of the alveolar liquid sample was measured. In an earlier study, we reported that the concentration of the protein tracers in the liquid sampled by a 3-mm catheter wedged into the distal airways was the same as in a directly obtained alveolar micropuncture sample (14). Extravascular lung water was measured on both lungs separately (see Measurements).

\section{Specific protocols}

Group 1A: Control sheep instilled with a protein solution alone (n $=13)$. After the baseline period, autologous serum $(n=4)$ or $5 \%$ ovine albumin solution $(n=9)$ was instilled into the right lower lobe. Then, the sheep were studied for $24 \mathrm{~h}$. After this time interval, the sheep were exsanguinated and processed as described above (see General protocol). The data for the control sheep instilled with either autologous serum $(n=4)$ or $5 \%$ ovine albumin $(n=9)$ have been combined because there was no significant difference between the results from the two group subsets (data not shown).

Group 1B: Control sheep instilled with P. aeruginosa bacteria (positive controls $)(n=5) .10 \mathrm{ml}$ of live $P$. aeruginosa $\left(10^{9} \mathrm{CFU} / \mathrm{ml}\right)$ were mixed with a $5 \%$ ovine albumin solution in Ringer's lactate and instilled into the right lower lobe. Then, the sheep were studied and processed as described above.

Group 2: Instillation of $P$. aeruginosa bacteria in sheep with circulating IgG antibody to $P$. aeruginosa $(n=7)$. Preimmune serum was obtained and the sheep were vaccinated intramuscularly with $100 \mu \mathrm{g}$ of the $P$. aeruginosa immunotype I high molecular weight polysaccharide once a week for $3 \mathrm{wk}(6)$. After $3 \mathrm{wk}$, an increase in the IgG antibody level to $P$. aeruginosa was measured in the circulating serum. Then, 10 $\mathrm{ml}$ of live $P$. aeruginosa $\left(10^{9} \mathrm{CFU} / \mathrm{ml}\right)$ was mixed with a $5 \%$ ovine albumin solution in Ringer's lactate and instilled into the right lower lobe. The sheep were then studied and processed as described above. To assess whether IgG antibody to $P$. aeruginosa entered the airspaces of the lung, both lungs of two additional vaccinated sheep were lavaged with $1,000 \mathrm{ml}$ of isotonic saline using $150-\mathrm{ml}$ aliquots. We recovered and pooled $750-800 \mathrm{ml}$ from each lung.

Group 3: Instillation of live P. aeruginosa bacteria in sheep with circulating and alveolar IgG antibody to $P$. aeruginosa $(n=9)$ ). Preimmune serum was obtained and the sheep were vaccinated intramuscularly with $100 \mu \mathrm{g}$ of the $P$. aeruginosa immunotype I high molecular weight polysaccharide once a week for $3 \mathrm{wk}$. After $3 \mathrm{wk}$, IgG antibody to $P$. aeruginosa level was measured in the circulating serum. Then, 10 $\mathrm{ml}$ of live $P$. aeruginosa $\left(10^{9} \mathrm{CFU} / \mathrm{ml}\right)$ was mixed with autologous hyperimmune serum and instilled into the right lower lobe. The sheep were studied and processed as described above.

Group 4: Instillation of $P$. aeruginosa bacteria in sheep with alveolar $I g G$ antibody to $P$. aeruginosa $(n=4)$. IgG was isolated from serum obtained from an immunized donor sheep (see preparation of instillate). Then, $1 \%$ IgG antibody to $P$. aeruginosa was mixed with ovine albumin and Ringer's lactate to prepare a $5 \%$ protein solution and instilled with $10 \mathrm{ml}$ of live $P$. aeruginosa $\left(10^{9} \mathrm{CFU} / \mathrm{ml}\right)$ into the right lower lobe of nonimmune sheep. The sheep were then studied and processed as described above. 
Group 5: Instillation of $P$. aeruginosa bacteria in sheep that were pretreated with alveolar IgG antibody to $P$. aeruginosa $(n=4)$. IgG was isolated from serum obtained from an immunized donor sheep (see Preparation of instillate). Then $4 \mathrm{ml} / \mathrm{kg}$ of $1 \% \mathrm{IgG}$ antibody was instilled into the right lower lobe of nonimmune sheep. The sheep were extubated after they were awake. $24 \mathrm{~h}$ later, $10 \mathrm{ml}$ of $10^{9} \mathrm{CFU} P$. aeruginosa was added to a $5 \%$ ovine albumin instillate and the instillate was placed in the same location in the right lower lobe as the IgG had been placed. The animal was again extubated after recovery and then studied and processed as in the other protocols.

\section{Measurements of hemodynamics}

Systemic arterial and airway pressures were measured continuously during the surgical preparation and the instillation of $P$. aeruginosa into the airspaces of the lung.

\section{Lung endothelial and alveolar epithelial barrier protein permeability}

Two different methods were used to measure the bidirectional flux of albumin across the lung epithelial barrier, as we have used before (1114). The first method required measurement of the residual ${ }^{125} \mathrm{I}$-albumin (the alveolar protein tracer) in the lung as well the accumulation of ${ }^{125} \mathrm{I}$-albumin in the plasma. The second method required the measurement of ${ }^{131} \mathrm{I}$-albumin (the vascular protein tracer) in the lungs and the airspace of the lung.

The total quantity of ${ }^{125} \mathrm{I}$-albumin (the alveolar protein tracer) instilled into the lung was determined by measuring duplicate samples of the instilled solution for total counts $(\mathrm{cpm} / \mathrm{g}$ ) and then multiplying this data by the total volume instilled into the lung. To calculate the residual ${ }^{125} \mathrm{I}$-albumin in the lung after $24 \mathrm{~h}$, the average radioactivity counts of two $0.5 \mathrm{-g}$ samples obtained from the lung homogenate (see below) were multiplied by the total volume of the lung homogenate. The ${ }^{125} \mathrm{I}$ albumin in the lung homogenate data was added to the recovered counts in the final aspirate of alveolar fluid to calculate the amount of instilled ${ }^{125} \mathrm{I}$-albumin that remained in the lung after $24 \mathrm{~h}$. The ${ }^{125} \mathrm{I}$-albumin in the circulating plasma was measured from a sample of plasma obtained at the end of the experiment. The plasma fraction was accounted for by multiplying the counts per milliliter times the plasma volume (body weight $\times 0.07$ [1 - hematocrit $]$ ).

The second method required measurement of the vascular protein tracer, ${ }^{131}$ I-albumin, in the final alveolar sample. The ${ }^{131} \mathrm{I}$-albumin counts in the plasma over the course of the experiment were averaged, and the ${ }^{131}$ I-albumin counts in the final airspace samples were expressed as a ratio to the plasma counts. Alveolar liquid was obtained by passing a 3-mm-diameter catheter into the distal airways of the instilled lung and aspirating 1-2 $\mathrm{ml}$ of alveolar fluid. The sample was centrifuged and the radioactivity (counts per milliliter) of the supernatant were measured. This ratio provided a good index of equilibration of the vascular protein tracer into the alveolar compartment, as we and other investigators have shown in other experimental studies of lung epithelial permeability $(12,13,15)$.

Also, the accumulation of the vascular protein tracer in the extravascular space of the lungs was used as an index of endothelial permeability. The accumulation of the vascular protein tracer, ${ }^{131} \mathrm{I}$-albumin, is expressed as milliliters and is calculated by determining the total extravascular counts of ${ }^{131} \mathrm{I}$-albumin in the lung divided by the average counts in the plasma over $24 \mathrm{~h}$, as we have done before (13).

Trichloracetic precipitation established that protein tracers in the instillate, alveolar liquid, and plasma were always $>98 \%$ protein bound.

Measurement of excess water in the lung and pleural space To determine the excess water in the lung and the pleural space after 24 $h$, we used the following methods. For determination of the excess extravascular water in the instilled versus the contralateral control lung, standard methods were used, as in our earlier studies (11-13, 16). Before exsanguination, a 40-ml blood sample was obtained to measure the hemoglobin concentration and the water/dry weight ratio of blood for the lung water calculation. Each lung was separately homogenized and the extravascular lung water was determined by calculating the water/dry weight ratio. Briefly, the volume of the excess extravascular lung water (ELW) ${ }^{1}$ of the instilled experimental lung was calculated as the difference between the water/dry weight ratios of the experimental and contralateral lungs multiplied by the dry weight of the experimental lung. The dry weight of the instilled experimental lung was corrected for the dry weight of the instilled protein remaining in the lung at the end of the experiment. To determine the mass of protein remaining, the dry weight of the instillate was multiplied by the fraction of ${ }^{125} \mathrm{I}-\mathrm{al}-$ bumin remaining in the lung. This value was then subtracted from the total dry weight of the experimental lung.

The equation is $\operatorname{ELW}(\mathrm{ml})=\left[W_{\mathrm{e}} /\left(D_{\mathrm{e}}-P\right)-W_{\mathrm{c}} / D_{\mathrm{c}}\right]\left(D_{\mathrm{e}}-P\right)$ in which $W$ and $D$ are extravascular lung water and blood-free dry weight of the experimental lung, e, and the control lung, c, $P$ is the blood-free dry weight of the instilled $5 \%$ ovine albumin solution multiplied by the fraction of ${ }^{125} \mathrm{I}$-albumin remaining in the lung after $24 \mathrm{~h}$. Our previous study demonstrated the importance of the pleural space as a pathway for draining excess fluid from the lung (17). Therefore in these studies, the final pleural water volume measured in the pleural space after $24 \mathrm{~h}$ has been added to the ELW to provide a more accurate indication of the total lung and pleural fluid balance.

\section{Measurement of IgG antibody to $P$. aeruginosa}

Plasma antibody levels to the immunotype 1 strain of $P$. aeruginosa were quantified by a radioactive antigen binding assay using intrinsically ${ }^{14} \mathrm{C}$-labeled high molecular weight polysaccharide prepared as previously described $(6,18)$.

\section{Growth and culturing of live $P$. aeruginosa}

A clinical isolate of $P$. aeruginosa, Fisher immunotype 1 was used for all these studies. These bacteria were maintained in peptone broth containing $25 \%$ glycerol at $-70^{\circ} \mathrm{C}$. Before an experiment, the broth was thawed and the organisms were transferred to blood agar plates (5\% sheep erythrocytes) for $24 \mathrm{~h}$. Overnight cultures were transferred to fresh medium, tryptone soy broth, for another $24 \mathrm{~h}$. On the day of experiment, the bacteria were sedimented in a clinical centrifuge and resuspended to a final concentration of $10^{9} \mathrm{CFU} / \mathrm{ml}$ in sterile PBS. Then, the Pseudomonas solution ( $10 \mathrm{ml}$ of $10^{9} \mathrm{CFU} / \mathrm{ml}$ ) was centrifuged at $1,500 \mathrm{~g}$ for $15 \mathrm{~min}$. The pellet of bacteria was washed twice with PBS, and was resuspended in $10 \mathrm{ml}$ of the same solution.

Before intraalveolar instillation, a sample was taken for quantitative culture. Samples of blood, pleural fluid, alveolar fluid, and lung homogenate were obtained aseptically for culture at the end of the experiments. The concentration of bacteria was then quantified by plating successive 10 -fold dilutions of the bacterial suspension onto sheep blood agar plates and by scoring visible colonies after $24 \mathrm{~h}$ incubation at $37^{\circ} \mathrm{C}$. All colonies were also subcultured to identify $P$. aeruginosa organisms. Routine biochemical screening and antibiotic sensitivity testing were done to ensure the $P$. aeruginosa strain has not changed between experiments.

\section{Statistics}

The data are summarized as mean and standard deviation. One-way analysis of variance followed by Scheffe $F$ test was used to compare the different animal groups. We regarded as statistically significant those differences with a $P$ value of $<0.05$ (19).

\section{Results}

Specific immunity. There was no detectable level of IgG antibody to $P$. aeruginosa in either the peripheral blood or in the alveolar fluid samples of the control sheep (group 1) that re-

\footnotetext{
1. Abbreviation used in this paper: ELW, excess extravascular lung water.
} 
ceived a protein solution alone or live $P$. aeruginosa (Table I). In contrast, after active immunization with immunotype I Pseudomonas polysaccharide antigen (group 2), the mean plasma concentration of IgG antibody to $P$. aeruginos $a$ was 3.7 $\mu \mathrm{g} / \mathrm{ml}$, with no antibody detected in these vaccinated group 2 sheep in the final alveolar fluid sample (Table I). In the group 3 sheep that were both immunized and instilled with immune serum, the concentration of IgG antibody was similar in the circulating plasma and the instilled immune serum (Table I). Interestingly, the concentration of $\mathrm{IgG}$ antibody to $P$. aeruginosa measured $24 \mathrm{~h}$ later in the final alveolar fluid samples of both groups 3,4 , and 5 were two to four times greater than those measured in the instillate (Table I), probably reflecting net alveolar liquid clearance, as in our earlier studies $(12,13)$.

Lung endothelial and epithelial permeability to protein. Instillation of live $P$. aeruginosa in a $5 \%$ ovine albumin solution into the airspaces of nonimmune sheep (group 1B) resulted in a twofold increase in the 24-h flux of the alveolar protein tracer ${ }^{125} \mathrm{I}$-albumin into the blood $(12 \pm 1 \%, P<0.05)$ and a correspondingly reduced recovery of ${ }^{125} \mathrm{I}$-albumin in the lung $(65 \pm 1 \%, P<0.05)$ compared with the sheep instilled with a protein solution alone (group 1A, Table II). The presence of circulating IgG antibody to $P$. aeruginosa (group 2 ) elicited by active immunization did not prevent the efflux of the alveolar protein tracer ${ }^{125} \mathrm{I}$-albumin out of the airspaces of the lung ( Table II). In contrast, when IgG antibody to $P$. aeruginosa was instilled with $P$. aeruginosa into the airspaces of vaccinated sheep as immune serum (group 3 ) or into the airspaces of nonimmune sheep as IgG antibody alone (group 4), or $24 \mathrm{~h}$ before bacterial instillation (group 5), there was no difference in the efflux of the alveolar protein tracer ${ }^{125} \mathrm{I}$-albumin compared with the control sheep (group 1A).

Table I. Specific Anti-Pseudomonas Antibody Levels in Peripheral Blood, Instilled Solution, and Final Alveolar Fluid

\begin{tabular}{|c|c|c|c|}
\hline Experimental condition & $\begin{array}{l}\text { Specific } \\
\text { antibody in } \\
\text { peripheral } \\
\text { blood }\end{array}$ & $\begin{array}{l}\text { Specific } \\
\text { antibody in } \\
\text { instilled } \\
\text { solution }\end{array}$ & $\begin{array}{l}\text { Specific } \\
\text { antibody in } \\
\text { alveolar } \\
\text { fluid }\end{array}$ \\
\hline & & $\mu g / m l$ & \\
\hline \multicolumn{4}{|l|}{ Controls (group 1) } \\
\hline $\begin{array}{l}\text { A. Protein solution } \\
\text { alone }(n=13)\end{array}$ & $<0.5$ & 0 & $<0.5$ \\
\hline $\begin{array}{l}\text { B. Live } P \text {. aeruginosa in } \\
5 \% \text { albumin }(n=5)\end{array}$ & $<0.5$ & 0 & $<0.5$ \\
\hline $\begin{array}{l}\text { Circulating antibody } \\
\text { alone } \\
\text { (group 2) }(n=5)\end{array}$ & $3.7+3.6^{*}$ & 0 & $<0.5$ \\
\hline $\begin{array}{l}\text { Circulating and } \\
\text { alveolar antibody } \\
\text { (group 3) }(n=9)\end{array}$ & $7.1 \pm 3.6^{*}$ & $6.6 \pm 4.3^{*}$ & $23.9 \pm 13.5^{*}$ \\
\hline $\begin{array}{l}\text { Alveolar IgG alone } \\
\text { (group 4) }\end{array}$ & & & \\
\hline$(n=4)$ & $<0.5$ & $44.5 \pm 45.7^{*}$ & $139.0 \pm 88.7^{*}$ \\
\hline $\begin{array}{l}\text { Pretreatment alveolar } \\
\quad \text { IgG alone } \\
\quad \text { (group 5) }(n=4)\end{array}$ & $<0.5$ & $10.8 \pm 0.5^{*}$ & $37.0 \pm 4.0^{*}$ \\
\hline
\end{tabular}

Mean \pm SD. ${ }^{*} P<0.05$ vs. controls.
Table II. Alveolar Protein Tracer ( ${ }^{125}$ I-Albumin) Remaining in the Lung after $24 \mathrm{~h}$ and Accumulated in the Bloodstream after $24 \mathrm{~h}$

\begin{tabular}{llc}
\hline & \multicolumn{2}{c}{$\begin{array}{c}\text { Alveolar protein tracer } \\
\text { (percent of instilled }\end{array}$} \\
\cline { 2 - 3 } Experimental condition & Lung & Blood \\
\hline $\begin{array}{l}\text { Controls (group 1) } \\
\text { A. Protein solution alone }(n=13)\end{array}$ & $78.3 \pm 7.1$ & $6.3 \pm 3.0$ \\
$\quad \begin{array}{l}\text { B. Live } P \text {. aeruginosa in 5\% } \\
\quad \text { albumin }(n=5)\end{array}$ & $64.8 \pm 1.0^{*}$ & $12.3 \pm 0.5^{*}$ \\
$\begin{array}{l}\text { Circulating antibody alone (group 2) } \\
\quad(n=5)\end{array}$ & $63.8 \pm 8.3^{*}$ & $13.0 \pm 6.4^{*}$ \\
$\begin{array}{l}\text { Circulating and alveolar antibody } \\
\quad \text { (group 3) }(n=9)\end{array}$ & $76.6 \pm 4.7$ & $7.9 \pm 1.9$ \\
$\begin{array}{l}\text { Alveolar IgG alone (group 4) }(n=4) \\
\text { Pretreatment alveolar lgG alone } \\
\quad \text { (group 5) }(n=4)\end{array}$ & $72.5 \pm 4.4$ & $6.3 \pm 2.4$ \\
\hline
\end{tabular}

Mean \pm SD. ${ }^{*} P<0.05$ vs. controls.

Instillation of $P$. aeruginosa solution into the airspaces of the lung of nonimmune sheep (group 1B) resulted in a significant increase in the influx of the vascular protein tracer ${ }^{131} \mathrm{I}$-albumin into the extravascular and alveolar spaces of the lung compared with control sheep (group 1A, Table III). The presence of circulating IgG antibody to $P$. aeruginosa (group 2) prevented the influx of the vascular protein tracer ${ }^{131} \mathrm{I}$-albumin into the interstitium of the lung, but not into the airspaces (Table III). In contrast, instillation of immune serum in vaccinated sheep (group 3 ) prevented influx of ${ }^{131} \mathrm{I}$-albumin into the interstitium and the airspaces (Table III). The instillation of IgG antibody to $P$. aeruginos $a$ into the airspaces concurrent (group 4) or $24 \mathrm{~h}$ before the bacterial instillation (group 5) prevented the influx of ${ }^{131} \mathrm{I}$-albumin into the airspaces of the

Table III. Vascular Protein Tracer (131 I-Albumin) Accumulation in the Extravascular and Alveolar Spaces of the Instilled Lung after $24 \mathrm{~h}$

\begin{tabular}{|c|c|c|}
\hline Experimental condition & $\begin{array}{l}\text { Accumulation of } \\
{ }^{131} \text { I-albumin } \\
\text { into the } \\
\text { extravascular } \\
\text { spaces of the } \\
\text { instilled lung* }\end{array}$ & $\begin{array}{c}\text { Alveolar } \\
\text { fluid/plasma } \\
\text { 131 I-albumin } \\
\text { ratio }\end{array}$ \\
\hline \multicolumn{3}{|l|}{ Controls (group 1) } \\
\hline $\begin{array}{l}\text { A. Protein solution alone }(n=13) \\
\text { B. Live } P \text {. aeruginosa in } 5 \%\end{array}$ & $11 \pm 5$ & $0.21 \pm 0.14$ \\
\hline albumin $(n=5)$ & $57 \pm 25^{\ddagger}$ & $0.47 \pm 0.13^{\ddagger}$ \\
\hline $\begin{array}{l}\text { Circulating antibody alone (group 2) } \\
\quad(n=5)\end{array}$ & $22 \pm 20$ & $0.40 \pm 0.11^{\ddagger}$ \\
\hline $\begin{array}{l}\text { Circulating and alveolar antibody } \\
\quad \text { (group 3) }(n=9)\end{array}$ & $21 \pm 10$ & $0.28 \pm 0.14$ \\
\hline Alveolar IgG alone (group 4) $(n=4)$ & $37 \pm 6^{\ddagger}$ & $0.33 \pm 0.03$ \\
\hline $\begin{array}{l}\text { Pretreatment alveolar IgG alone } \\
\quad \text { (group 5) }(n=4)\end{array}$ & $27 \pm 6$ & $0.30 \pm 0.02$ \\
\hline
\end{tabular}

Mean $\pm \mathrm{SD} ;{ }^{*}$ Expressed as plasma equivalents $(\mathrm{ml})$ calculated by ${ }^{131} \mathrm{I}$-albumin in extravascular spaces (cpm) divided by mean ${ }^{131} \mathrm{I}$-albumin in plasma (cpm/g). ${ }^{\ddagger} P<0.05$ vs. controls. 


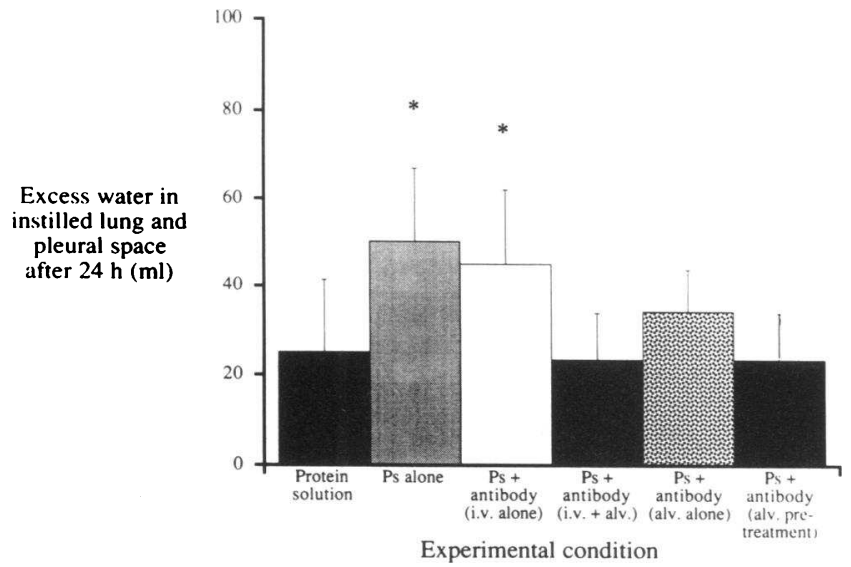

Figure 1. Extravascular water content of the instilled lung and the adjacent pleura space (mean $\pm S D$ ) is shown for all experimental groups. The quantity of excess water in the instilled lung and the pleural space $24 \mathrm{~h}$ after instillation of $P$. aeruginosa (group 1B) was significantly increased compared with the control studies (group 1A). The sheep with circulating IgG antibody to $P$. aeruginosa alone (group 2) had a similar increase in excess water in the lung and pleural space after $24 \mathrm{~h}$. In contrast, concurrent instillation of IgG antibody to $P$. aeruginosa into the airspaces (groups 3 and 4 ) or pretreatment with IgG antibody (group 5) prevented any significant increase in excess water in the lung and pleural space.

nonimmune sheep (Table III). The group 4 sheep still had a slight increase in the influx of plasma into the interstitium of the lung, but this effect was not present in the group 5 sheep that were treated with IgG $24 \mathrm{~h}$ before the instillation of the bacteria (Table III).

Lung and pleural fluid balance. The quantity of excess water remaining in the instilled lung and the pleural space after $24 \mathrm{~h}$ after instillation of $P$. aeruginosa (group 1B) was more than double the volume recovered in control studies (group 1A) (Fig. 1). The sheep with circulating antibody alone (group 2 ) had a similar increase in excess water in the lung and pleural space after $24 \mathrm{~h}$ (Fig. 1). However, the presence of IgG antibody to $P$. aeruginosa in the circulation and the airspaces (group 3) was not associated with any increase in excess water (Fig. 1). IgG antibody to $P$. aeruginosa instilled in the air- spaces with the bacteria (group 4) was associated with a $60 \%$ mean reduction in excess water and pretreatment with specific IgG $24 \mathrm{~h}$ before bacterial instillation (group 5) was not associated with any increase in the excess water (Fig. 1).

Protein permeability across the pleura. Instillation of $P$. aeruginosa into the airspaces of the lung of nonimmune sheep (group 1B) was associated with a significant movement (10fold increase) of both alveolar protein tracer and the vascular protein tracer (2-fold increase) into the pleural space adjacent to the instilled lung (Table IV). The presence of circulating IgG antibody to $P$. aeruginosa (group 2 ) did not prevent this increased influx of the alveolar and vascular protein tracers into the pleural space. However, when immune serum was instilled in the vaccinated sheep (group 3 ) or IgG antibody to $P$. aeruginosa was instilled with $P$. aeruginosa into the airspaces of nonimmune sheep (group 4 ), or $24 \mathrm{~h}$ before bacterial instillation (group 5), the influx of the alveolar protein tracer into the pleural space was completely prevented (Table IV).

The protein concentration of the pleural fluid adjacent to the instilled lung was significantly increased in the nonimmune sheep instilled with $P$. aeruginosa (group 1B) and in the sheep with only circulating antibody (group 2) (Table IV). In contrast, in groups 3,4 , and 5 , the protein concentration in the pleural fluids did not increase (Table IV).

Also, the volume of the pleural fluid adjacent to the instilled lung was $5.4 \pm 3.0 \mathrm{ml}$ in the control sheep instilled with a protein solution alone (group 1A) (Table IV). The mean volume of the pleural fluid doubled in the nonimmune sheep instilled with $P$. aeruginosa (group 1B) and in the vaccinated sheep with circulating IgG antibody to $P$. aeruginosa (group 2 ); however, the volume of pleural fluid was normal in groups 3,4 , and 5 (Table IV).

Bacteriological cultures. The number of colony-forming units of bacteria instilled into the airspaces of the lung was similar in all the $P$. aeruginosa experiments (Table V). The final number of bacteria measured in the lung homogenate was similar in the nonimmune sheep that received $P$. aeruginosa (group 1B) and those sheep with only circulating IgG antibody to $P$. aeruginosa (group 2) (Table V). In contrast, when IgG antibody to $P$. aeruginosa was present in the instilled solution in either the immune, vaccinated sheep (group 3 ) or in the nonvaccinated sheep (group 4), there was at least a 10 -fold

Table IV. Accumulation of alveolar $\left({ }^{125}\right.$ I-Albumin) and Vascular $\left({ }^{131}\right.$ I-Albumin) Protein Tracers and Native Protein Concentration in the Pleural Space of the Instilled Lung over $24 \mathrm{~h}$

\begin{tabular}{|c|c|c|c|c|}
\hline Experimental condition & $\begin{array}{c}\text { Alveolar } \\
\text { protein } \\
\text { tracer in } \\
\text { pleura fluid }\end{array}$ & $\begin{array}{c}\text { Pleura } \\
\text { fluid/plasma } \\
\text { 131-albumin } \\
\text { ratio }\end{array}$ & $\begin{array}{l}\text { Native protein } \\
\text { concentration } \\
\text { in pleura fluid }\end{array}$ & $\begin{array}{l}\text { Volume } \\
\text { of pleural } \\
\text { effusion }\end{array}$ \\
\hline & \% of instilled & & $\mathrm{g} / 100 \mathrm{ml}$ & $m l$ \\
\hline \multicolumn{5}{|l|}{ Controls (group 1) } \\
\hline A. Protein solution alone $(n=13)$ & $0.03 \pm 0.06$ & $0.20 \pm 0.09$ & $1.7 \pm 0.8$ & $5.7 \pm 3.1$ \\
\hline B. Live $P$. aeruginosa in $5 \%$ albumin $(n=5)$ & $0.38 \pm 0.55^{*}$ & $0.37 \pm 0.08^{*}$ & $3.2 \pm 1.1^{*}$ & $10.3 \pm 9.6$ \\
\hline Circulating antibody alone (group 2) $(n=5)$ & $0.34 \pm 0.25^{*}$ & $0.39 \pm 0.10^{*}$ & $4.2 \pm 1.2^{*}$ & $15.0 \pm 15.8^{*}$ \\
\hline Circulating and alveolar antibody (group 3$)(n=9)$ & $0.06 \pm 0.08$ & $0.30 \pm 0.13$ & $1.9 \pm 0.9$ & $6.4 \pm 3.5$ \\
\hline Alveolar IgG alone (group 4) $(n=4)$ & $0.05 \pm 0.03$ & $0.32 \pm 0.09^{*}$ & $2.6 \pm 1.0$ & $7.2 \pm 2.7$ \\
\hline Pretreatment alveolar IgG alone (group 5) $(n=4)$ & $0.02 \pm 0.01$ & $0.24 \pm 0.12$ & $1.7 \pm 1.1$ & $2.9 \pm 0.9$ \\
\hline
\end{tabular}

Mean \pm SD. ${ }^{*} P<0.05$ vs. controls. 
decrease in the number of microorganisms recovered after $24 \mathrm{~h}$ ( Table V). In the pretreated sheep (group 5), there was a twofold reduction in the number of organisms recovered after $24 \mathrm{~h}$. The instillation of the IgG antibody to $P$. aeruginosa also prevented the dissemination of $P$. aeruginosa to the pleural space, as confirmed by the negative pleural fluid cultures obtained after $24 \mathrm{~h}$ in all but 1 of 13 sheep (groups 3, 4, and 5) (Table V). In contrast, when $P$. aeruginosa was instilled without specific antibody in the nonimmune sheep (group 1B) and in the sheep with only circulating antibody (group 2), 50\% of the pleural fluid cultures were positive for $P$. aeruginos $a$ at the end of the experiment. Blood cultures were sterile in all the experiments.

\section{Discussion}

The first objective of these studies was to determine the effect of circulating IgG antibody to $P$. aeruginosa in modifying the homologous bacterial injury to the different barriers of the lung. The vaccinated sheep (group 2 ) developed levels of circulating specific antibody that have been shown to be protective (6) (Table I). However, no detectable quantity of IgG antibody to $P$. aeruginosa was found in the final alveolar sample (Table I). The lack of bacterial killing in the final alveolar sample from these sheep (Table V) also indicates that very little of the $\mathrm{IgG}$ antibody to $P$. aeruginosa entered the airspaces of the lung. Therefore, the inability of significant quantities of IgG antibody to $P$. aeruginosa to penetrate into the airspaces probably accounts for the lack of protection in the group 2 sheep against injury to the epithelial and pleural barriers.

There are three possible explanations for the finding that IgG antibody to $P$. aeruginosa in the circulation did not enter the airspaces of the vaccinated sheep in significant quantity. Although a small quantity of ${ }^{131} \mathrm{I}$-albumin entered the airspaces from the plasma, the epithelial leak produced by the airspace bacteria might have been inadequate to allow the entry of

Table V. Bacteriological Cultures of Instillate and the Lung Homogenate and Pleural Fluid of the Instilled Lung after $24 \mathrm{~h}$

\begin{tabular}{|c|c|c|c|}
\hline Experimental condition & $\begin{array}{c}\text { Organisms } \\
\text { instilled }\end{array}$ & $\begin{array}{l}\text { Organisms } \\
\text { obtained } \\
\text { in the } \\
\text { instilled } \\
\text { lung }\end{array}$ & $\begin{array}{l}\text { Qualitative } \\
\text { culture } \\
\text { of pleural } \\
\text { fluid }\end{array}$ \\
\hline & \multicolumn{2}{|c|}{$C F U \times 10^{9} / \mathrm{kg}$} & \\
\hline Controls (group 1) & & & \\
\hline $\begin{array}{l}\text { A. Protein solution alone } \\
(n=13)\end{array}$ & 0 & 0 & $0 / 13$ \\
\hline $\begin{array}{l}\text { B. Live } P \text {. aeruginosa in } 5 \% \\
\text { albumin }(n=5)\end{array}$ & $0.5 \pm 0.2$ & $0.7 \pm 0.7$ & $3 / 5$ \\
\hline $\begin{array}{l}\text { Circulating antibody alone } \\
\quad \text { (group 2) }(n=5)\end{array}$ & $0.4 \pm 0.1$ & $1.0 \pm 1.4$ & $2 / 5$ \\
\hline $\begin{array}{l}\text { Circulating and alveolar } \\
\text { antibody (group 3) }(n=9)\end{array}$ & $0.6 \pm 0.5$ & $0.01 \pm 0.01^{*}$ & $0 / 9$ \\
\hline $\begin{array}{l}\text { Alveolar IgG alone (group 4) } \\
\quad(n=4)\end{array}$ & $0.9 \pm 0.5$ & $0.03 \pm 0.05^{*}$ & $1 / 4$ \\
\hline $\begin{array}{l}\text { Pretreatment alveolar IgG alone } \\
\quad \text { (group 5) }(n=4)\end{array}$ & $0.5 \pm 0.3$ & $0.2 \pm 0.07^{*}$ & $0 / 4$ \\
\hline
\end{tabular}

Mean \pm SD. ${ }^{*} P<0.05$ vs. live $P$. aeruginosa in $5 \%$ albumin. much of the larger plasma IgG. In fact, a recent study from our laboratory has documented that protein movement across the alveolar epithelial barrier is inversely related to molecular size (20). Another possibility is that some IgG antibody to $P$. aeruginosa entered the airspaces and was cleaved by $P$. aeruginosa elastase, as has been shown by others (21). Finally, some of the IgG antibody to $P$. aeruginos $a$ may have entered the airspaces and was complexed to other proteins and, therefore, would not have been detected by the radioimmunoassay that we used. We investigated this possibility and could not find immune complexes.

Our results differ from those of two previous studies conducted in small animals in which active or passive immunization against $P$. aeruginosa increased the pulmonary clearance of these bacteria $(22,23)$. This difference may be explained first by the fact that, in sheep, the intraalveolar administration of $P$. aeruginosa did not cause a rapid fatal disease as reported for smaller animals $(22,23)$. Therefore, our animal model may be more representative of critically ill patients who develop a nosocomial pneumonia since the airways of these patients are progressively colonized with Pseudomonas bacteria before the pneumonia becomes clinically apparent (24). Secondly, since the lung injury was much more severe in the smaller animal studies, the influx of plasma proteins into the airspaces of the lung should have been greater, explaining why there was an increased quantity of IgG antibody to $P$. aeruginosa at the end of the studies in the airspaces of both immunized mice (23) and guinea pigs (22) compared with the level of IgG antibody to $P$. aeruginosa that we measured in the airspaces of our immunized sheep. However, the IgG antibody to $P$. aeruginosa was not increased in the bronchoalveolar lavage carried out before the instillation of bacteria in the immunized mice, indicating that the active immunization itself did not increase the $\mathrm{IgG}$ in the airspaces of the lung (23). In addition, in these immunized mice, the number of bacteria in the lung over $6 \mathrm{~h}$ multiplied significantly, suggesting that the transfer of the $\mathrm{IgG}$ from the vascular space to the airspaces of the lung after the intraalveolar $P$. aeruginosa challenge was not sufficient to enhance bacterial killing (23). Finally, in the previously cited studies, the most important effect of active immunization against $P$. aeruginosa bacteria was not a decrease in the lung damage caused by these bacteria, but a reduction in the overall mortality. This improved survival rate reported in small immunized animals seems to have been primarily related to the fact that circulating IgG antibody to $P$. aeruginos $a$ prevented death from sepsis by improving clearance of $P$. aeruginosa from the bloodstream.

Although active immunization against $P$. aeruginosa in our sheep model was useful in decreasing lung vascular injury, it was of no value in preventing the bacterial injury to the alveolar epithelium as well as the formation of protein-rich, culturepositive pleural effusions. In contrast, when IgG antibody to $P$. aeruginosa was present in both the circulation and the airspaces in the vaccinated sheep instilled with immune serum (group 3), there was complete protection against all lung and pleural injury (Tables II, III, and IV, and Fig. 1) and a markedly enhanced killing of bacteria (Table V). On the basis of complement depletion studies done in three sheep (data not shown), this effect did not depend on the presence of complement. In previous experiments, complement removal in neutropenic mice did not affect the protection offered by specific circulating IgG or IgA to $P$. aeruginosa (25). Also, instillation of nonimmune serum with the bacteria in preliminary sheep 
studies was not associated with a reduction in injury or greater bacterial killing compared with instillation of $P$. aeruginosa in a 5\% ovine albumin solution (data not shown). Therefore, these results strongly suggested that the primary protective factor in the group 3 sheep was the presence of IgG antibody to $P$. aeruginosa in the airspaces of the sheep lung. Therefore, the group 4 and group 5 studies using airspace instillation of IgG antibody to $P$. aeruginosa were designed to test this hypothesis.

Concurrent and prophylactic administration of IgG antibody to $P$. aeruginosa into the airspaces (groups 4 and 5 ) was not associated with any injury to the alveolar epithelial barrier nor the formation of culture-positive, exudative pleural effusions (Tables II, III, and IV). This protective effect was associated with increased killing of the bacteria in the airspaces ( Table V) and no increase in the excess water in the lung and pleural space (Fig. 1). The instillation of IgG antibody to $P$. aeruginosa in the airspaces concurrently with the bacteria instillation was still associated with a small accumulation of the vascular tracer, ${ }^{131} \mathrm{I}$-albumin, in the extravascular space of the lung. However, the ratio of the ${ }^{131} \mathrm{I}$-albumin in the alveolar fluid compared with plasma was not different from the control experiments ( Table III). This result suggests that, although the concurrent administration of specific IgG with the bacteria optimally increased bacterial killing and prevented alveolar epithelial and pleural injury, a mild increase in lung endothelial permeability still occurred. Interestingly, pretreatment with IgG $24 \mathrm{~h}$ before the instillation of live $P$. aeruginosa (group 5) prevented the increase in lung endothelial permeability. This effect may have occurred because the 24 -h pretreatment interval allowed time for some of the IgG instilled into the airspaces to cross the alveolar epithelial barrier and enter both the lung interstitium and the circulation, as we have reported occurs after instillation of various peptides into the airspaces of the normal lung $(20,26,27)$.

What is the significance of these results? First, the data clearly demonstrate that specific immunotherapy administered through the respiratory tract prevented the bacterial injury to the alveolar epithelium in healthy sheep. The pathogenic and prognostic significance of injury to the alveolar epithelial barrier has recently been examined in a prospective study of patients with acute lung injury (28). In that clinical study, recovery of alveolar epithelial barrier function in patients with alveolar flooding and acute lung injury was associated with an excellent prognosis for resolution of lung injury and recovery from respiratory failure.

Secondly, specific immunotherapy also prevented the dissemination of $P$. aeruginosa bacteria to the pleural space as well as the formation of protein-rich effusions. This protective effect was observed in nonimmune sheep instilled with IgG antibody with the bacteria or when the antibody was instilled $24 \mathrm{~h}$ before the bacterial instillation (groups 4 and 5). There was no protective effect in the vaccinated animals instilled with live $P$. aeruginosa bacteria in 5\% ovine albumin solution (group 2). This result confirms that the presence of circulating antibody alone is not sufficient to prevent the local dissemination of $P$. aeruginosa to the pleural space. Since the instillation of IgG antibody to $P$. aeruginosa into the alveoli was associated with an increase in the pulmonary clearance of $P$. aeruginosa bacteria (Table $\mathrm{V}$ ), the dissemination of these bacteria to the pleural space may not occur before the quantity of bacteria present into the airspaces of the lung has reached a critical level. In fact, preliminary experiments in our laboratory have shown that after $10^{7} \mathrm{cfu}$ of $P$. aeruginosa was instilled into rabbit lungs, the bacteria did not enter the pleural space (29). In contrast, when $10^{9} P$. aeruginosa was instilled, the bacteria uniformly disseminated to the pleural space (29). The development of protein-rich empyema after induction of an experimental $P$. aeruginosa pneumonia is probably explained by injury to the epithelial barrier with subsequent movement of alveolar fluid, bacteria, and some interstitial fluid to the pleural space.

We conclude that the prophylactic or concurrent instillation of IgG antibody to $P$. aeruginosa into the airspaces of the lung is beneficial for preventing injury to the alveolar epithelial barrier and the development of pleural infection associated with instillation of $10^{10} P$. aeruginosa organisms. Also, the intraalveolar administration of the IgG antibody to $P$. aeruginosa optimally increased lung bacterial killing. This study also demonstrated the inability of circulating IgG antibody $P$. aerugin$o s a$ to protect against lung epithelial and pleural injury probably because not enough IgG antibody enters the airspaces in the presence of moderate lung injury. These results may explain why $P$. aeruginosa can colonize patients so effectively; specific antibody may not enter the airspaces until the inoculum of $P$. aeruginosa has caused severe injury to the pulmonary epithelial barrier. Therefore, circulating IgG antibody is primarily available to aid in lung defense after more severe lung injury has occurred and larger amounts of circulatory plasma have entered the airspaces of the lung. The possible value of intraalveolar administration of $\mathrm{IgG}$ antibody to $P$. aeruginosa for preventative or therapeutic purposes deserves further study.

\section{Acknowledgments}

The authors thank Oscar Osorio and Paul Sumner for their technical assistance in carrying out these studies and Carol Baumeister for her assistance in preparing this manuscript.

This work was primarily supported by National Heart, Lung, and Blood Institute SCOR grant HL-19155 and by National Institute of Allergy and Infectious Diseases grant AI-22535. Dr. Pittet was supported by a Fellowship from the Swiss National Science Foundation and an ICI Fellowship from the Surgical Infection Society-Europe.

\section{References}

1. Horan, T. C., J. W. White, W. R. Jarvis, T. G. Emori, D. H. Culver, V. P. Munn, C. Thornsberry, D. R. Olson, and J. M. Hughes. 1986. Nosocomial infection surveillance 1984. Center for Disease Control Surveillance Summary. 32:1SS-16SS.

2. Bryan, C. S., and K. L. Reynolds. 1984. Bacteremic nosocomial pneumonia. Analysis of 172 single episodes from one metropolitan area. Am. Rev. Respir. Dis. 129:668-671.

3. Young, L. S. 1972. Human immunity to Pseudomonas aeruginosa. II: relationship between heat-stable opsonins and type specific lipopolysaccharides. J. Infect. Dis. 126:277-287.

4. Reynolds, H. Y., J. A. Kazmierowski, and H. H. Newball. 1975. Specificity of opsonic antibodies to enhance phagocytosis of Pseudomonas aeruginosa by human alveolar macrophages. J. Clin. Invest. 56:376-385.

5. Bjornson, A. B., and J. G. Michael. 1972. Contribution of humoral and cellular factors to the resistance to experimental infection by Pseudomonas aeruginosa in mice. II: opsonic, agglutinative, and protective capacities of immunoglobulin $\mathrm{G}$ anti-Pseudomonas antibodies. Infect. Immun. 5:775-782.

6. Pier, G. B. 1982. Safety and immunogenicity of high molecular weight polysaccharide vaccine from immunotype 1 Pseudomonas aeruginosa. J. Clin. Invest. 69:303-308.

7. Pier, G. B. 1986. Structural analysis and immunogenicity of Pseudomonas aeruginosa immunotype 2 high-molecular weight polysaccharide. J. Clin. Invest. 77:491-495.

8. Pollack, M., A. I. Huang, R. K. Prescott, L. S. Young, K. W. Hunter, D. F. Cruess, and C. M. Tsai. 1983. Enhanced survival in Pseudomonas aeruginosa septicemia associated with high levels of circulating antibody to Escherichia coli endotoxin core. J. Clin. Invest. 72:1874-1881. 
9. Pier, G. B., and M. Pollack. 1989. Isolation, structure, and immunogenicity of Pseudomonas aeruginosa immunotype 4 high-molecular weight polysaccharide. Infect. Immun. 57:426-431.

10. Pennington, J. E., G. B. Pier, J. C. Sadoff, and G. J. Small. 1986. Active and passive immunization strategies for Pseudomonas aeruginosa pneumonia. Rev. Infect. Dis. 8:S426-S433.

11. Matthay, M. A., Y. Berthiaume, and N. C. Staub. 1985. Long-term clearance of liquid and protein from the lungs of unanesthetized sheep. J. Appl. Physiol. 59:928-934.

12. Berthiaume, Y., N. C. Staub, and M. A. Matthay. 1987. Beta-adrenergic agonists increase lung liquid clearance in anesthetized sheep. J. Clin. Invest. 79:335-343.

13. Wiener-Kronish, J. P., K. H. Albertine, and M. A. Matthay. 1991. Differential responses of the endothelial and epithelial barriers of the lung in sheep to Escherichia coli endotoxin. J. Clin. Invest. 88:864-875.

14. Berthiaume, Y., V. C. Broaddus, M. A. Gropper, T. Tanita, and M. A. Matthay. 1988. Alveolar liquid and protein clearance from normal dog lungs. $J$. Appl. Physiol. 65:585-593.

15. Nelson, R. M., B. R. McIntyre, and E. A. Egan. 1978. Solute permeability of the alveolar epithelium in alloxan edema in dogs. J. Appl. Physiol. 44:353-357.

16. Selinger, S. L., R. D. Bland, R. H. Demling, and N. C. Staub. 1975. Distribution volumes of ${ }^{131} \mathrm{I}$-albumin, ${ }^{14} \mathrm{C}$-sucrose and ${ }^{36} \mathrm{Cl}$ in sheep. J. Appl. Physiol. 39:773-779.

17. Wiener-Kronish, J. P., V. C. Broaddus, K. H. Albertine, M. Gropper, M. A. Matthay, and N. C. Staub. 1988. Pleural effusions are associated with increased permeability pulmonary edema in anesthetized sheep. J. Clin. Invest. 82:1422-1429.

18. Pier, G. B. 1982. Cross-protection by Pseudomonas aeruginosa polysaccharides. Infect. Immun. 34:1117-1122.

19. Zar, J. H. 1974. Biostatistical Analysis. Prentice Hall, Inc., Englewood Cliffs, NJ.

20. Hastings, R. H., L. Grady, T. Sakuma, and M. A. Matthay. 1992. Clear- ance of different-sized proteins from the alveolar space in humans and rabbits. $J$. Appl. Physiol. 73:1310-1316.

21. Fick, R. B., G. P. Nage, S. U. Squier, R. E. Wood, J. B. L. Ggee, and H. Y. Reynolds. 1984. Proteins of the cystic fibrosis respiratory tract: fragmented IgG opsonic antibody causing defective opsonophagocytosis. J. Clin. Invest. 74:236248.

22. Pennington, J. E., G. J. Small, M. E. Lostrom, and G. B. Pier. 1986. Polyclonal and monoclonal antibody therapy for experimental Pseudomonas aeruginosa pneumonia. Infect. Immun. 54:239-244.

23. Dunn, M. M., G. B. Toews, D. Hart, and A. K. Pierce. 1985. The effects of systemic immunization on pulmonary clearance of Pseudomonas aeruginosa. Am. Rev. Respir. Dis. 131:426-431.

24. Gleeson, K., and H. Y. Reynolds. 1992. Pneumonia in the intensive care unit setting. J. Intensive Care Med. 7:24-35.

25. Pier, G. B., D. Thomas, G. Small, A. Siadak, and H. Zweerink. 1989. In vitro and in vivo activity of polyclonal and monoclonal human immunoglobulins G, M, and A against Pseudomonas aeruginosa lipopolysaccharide. Infect. Immun. 57:174-179.

26. Hubbard, R. C., M. A. Casolaro, M. Mittchell, S. E. Sellers, F. Arabia M. A. Matthay, and R. G. Crystal. 1989. Fate of aerosolized recombinant DNAproduced a l-antitrypsin: use of the epithelial surface of the lower respiratory tract to administer proteins of therapeutic importance. Proc. Natl. Acad. Sci. USA. 86:680-684.

27. Berthiaume, Y., K. H. Albertine, M. Grady, G. Flick, M. A. Matthay. 1989. Protein clearance from the air spaces and lungs of unanesthetized sheep over 144 h. J. Appl. Physiol. 67:1887-1897.

28. Matthay, M. A., and J. P. Wiener-Kronish. 1990. Intact epithelial barrier function is critical for the resolution of alveolar edema in man. Am. Rev. Respir. Dis. 142:1250-1257.

29. Wiener-Kronish, J. P., T. Sakuma, J. F. Pittet, R. Shanks, P. Summer, and M. A. Matthay. 1992. The dose-related effect of Pseudomonas aeruginosa on alveolar epithelial protein permeability and formation of exudative pleural effusions in rabbits. Clin. Res. 39:A264. (Abstr.) 